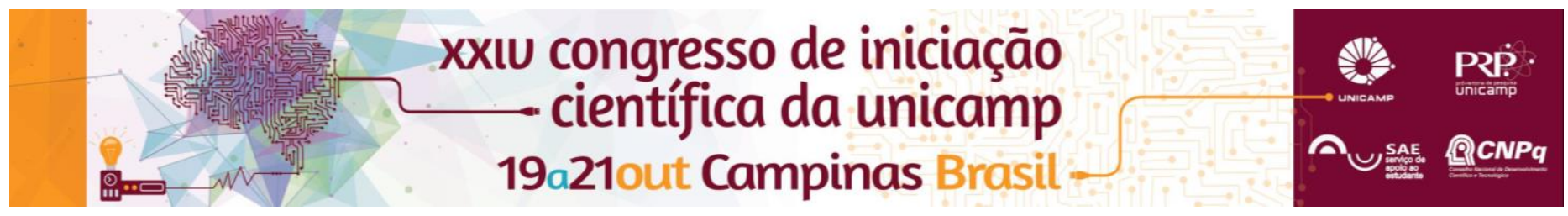

\title{
Microencapsulação de oleoresina de gengibre utilizando lipídios como material de parede
}

\author{
Caroline M. Paredes*, Vivian B. Oriani, Miriam D. Hubinger
}

\section{Resumo}

O presente estudo teve como objetivo produzir e caracterizar micropartículas lipídicas contendo oleoresina de gengibre (OG) $(10 \% \mathrm{~m} / \mathrm{m})$ utilizando o processo de spray chilling. Os lipídios ácido graxo palmítico (AP) e ácido graxo esteárico (AE) foram utilizados como carreadores para garantir a formação estrutural da partícula. $O$ ácido graxo oleico (AO) foi adicionado a fim de verificar o efeito na retenção dos compostos essenciais da oleoresina nas micropartículas lipídicas. A adição do ácido oleico não influenciou significativamente na retenção dos compostos de pungência, porém apresentou efeito na morfologia e na cristalização e fusão das partículas. As partículas com ácido esteárico apresentaram aumento de tamanho significativo conforme houve a adição do ácido oleico.

\section{Palavras-chave: \\ Micropartícula lipídica, spray chilling, oleoresina de gengibre.}

\section{Introdução}

O gengibre (Zingiber officinale) é uma das especiarias mais utilizada no mundo devido aos seus compostos aromáticos voláteis e de pungência ${ }^{(1)}$. Um ingrediente de interesse para a indústria alimentícia como substituto da raiz de gengibre "in natura" é a sua oleoresina, responsável pelo aroma e sabor característico do gengibre. Entretanto, ela apresenta sensibilidade quando exposta às condições adversas de armazenagem.

A utilização do processo de spray chilling para microencapsulação da oleoresina de gengibre é uma alternativa interessante a esse desafio em comparação às técnicas convencionais, como spray drying, devido ao seu baixo custo, processo contínuo e facilidade de produção em larga escala ${ }^{(2)}$, além de apresentar bons níveis de retenção de componentes principais e propiciar diferentes aplicações para as partículas, como em alimentos com alto teor de gordura, sopas em pó e produtos de panificação.

\section{Resultados e Discussão}

No estudo do comportamento térmico, observou-se que o ponto de fusão (PF) e o índice de cristalização (IC) diminuíram com a adição do ácido oleico e que, portanto, a presença do mesmo altera as estruturas cristalinas das micropartículas lipídicas (Tabela 1).

Quanto à retenção dos dois principais compostos de pungência presentes na oleoresina de gengibre (6-gingerol (6G) e 6-shogaol (6S)), não houve diferença significativa $(p<0.05)$ da quantidade retida entre as formulações contendo ácido palmítico e entre aquelas contendo ácido esteárico como agentes carreadores sólidos. Além disso, a adição de diferentes concentrações de ácido oleico não influenciou na retenção desses compostos na matriz lipídica (Tabela 1). Todas as formulações apresentaram retenção próxima a $100 \%$, o que pode estar relacionado com a afinidade entre os compostos de pungência e os ácidos graxos palmítico e esteárico.

Em todas as formulações estudadas, as micropartículas apresentaram ampla distribuição de diâmetro médio $\left(D_{4,3}\right)$, variando entre 35 e $42 \mu \mathrm{m}$, característico do processo de atomização na produção de micropartículas.
Tabela 1. Caracterização física das micropartículas

\begin{tabular}{|c|c|c|c|c|c|}
\hline \multirow[t]{2}{*}{ Ensaios } & \multicolumn{2}{|c|}{$\begin{array}{c}\text { Retenção } \\
(\%)\end{array}$} & \multirow{2}{*}{$\begin{array}{c}\text { PF } \\
\left({ }^{\circ} \mathrm{C}\right)\end{array}$} & \multirow{2}{*}{$\begin{array}{c}\text { IC } \\
(\%)\end{array}$} & \multirow{2}{*}{$\begin{array}{l}D_{4,3} \\
(\mu \mathrm{m})\end{array}$} \\
\hline & $6 \mathrm{G}$ & $6 S$ & & & \\
\hline $90 \%$ AP & $98 \pm 3^{a}$ & $99 \pm 3^{a}$ & $57,3 \pm 0,1$ & $97,3 \pm 1,6$ & $35 \pm 3^{6}$ \\
\hline $85 \% A P+5 \% A O$ & $98 \pm 5^{a}$ & $99 \pm 6^{a}$ & $55,5 \pm 0,1$ & $96,9 \pm 1,1$ & $36 \pm 4^{b}$ \\
\hline $75 \% A P+15 \% A O$ & $97 \pm 7^{a}$ & $98 \pm 3^{a}$ & $52,2 \pm 0,2$ & $89,9 \pm 1,8$ & $36 \pm 5^{b}$ \\
\hline $90 \% \mathrm{AE}$ & $99 \pm 2^{a}$ & $99 \pm 1^{a}$ & $63,8 \pm 0,4$ & $98,3 \pm 1,6$ & $37 \pm 3^{b}$ \\
\hline $85 \% A E+5 \% A O$ & $98 \pm 2^{a}$ & $99 \pm 1^{a}$ & $62,3 \pm 0,5$ & $95,5 \pm 1,4$ & $36 \pm 3^{b}$ \\
\hline $75 \% A E+15 \% A O$ & $99 \pm 1^{a}$ & $99 \pm 3^{a}$ & $58,3 \pm 0,2$ & $92,0 \pm 2,7$ & $42 \pm 3^{a}$ \\
\hline
\end{tabular}

Se tratando da morfologia, as micropartículas com ácido oleico apresentaram superfície mais rugosa, podendo ser decorrente da diminuição do ponto de fusão (Figura 1).

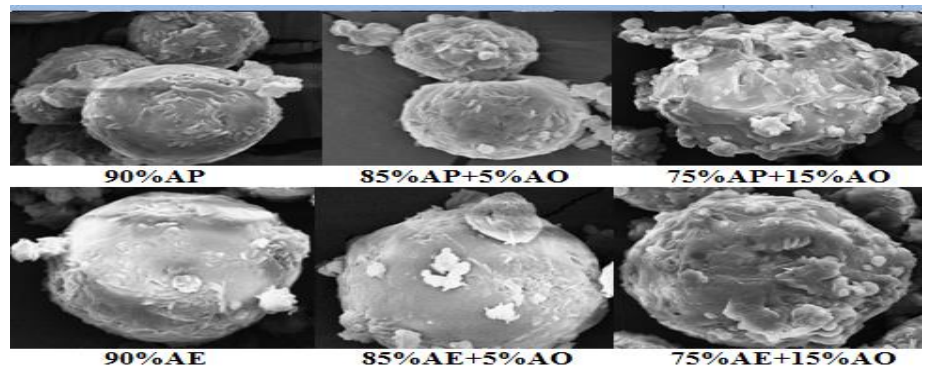

Figura 1. Morfologia das micropartículas lipídicas

\section{Conclusões}

A adição do ácido oleico e a própria oleoresina de gengibre alteraram a organização das micropartículas lipídicas, diminuindo seu índice de cristalização e, consequentemente, seu ponto de fusão. Porém, isso não resultou em maior retenção dos compostos de pungência do gengibre, que foi próxima a 100\% em todas as formulações estudadas. Dessa forma, a técnica de spray chilling permite o uso da oleoresina na forma em pó sem a perda dos seus principais compostos de pungência.

\footnotetext{
${ }^{1}$ JANGAM, S. V.; THORAT, B. N. Optimization of Spray Drying of Ginger Extract. Drying Technology, v. 28, n. 12, p. 1426-1434, 2010

${ }^{2}$ OKURO, P. K.; JUNIOR, F. E. M.; TRINDADE, C. S. F. Technological Challenges for Spray Chilling Encapsulation of Functional Food Ingredients. Food Technology and Biotechnology, v.51, n. 2, p. 171-182, 2013.
} 